\title{
Editorial
}

\section{IAPs, TNF, inflammation and Jürg TSCHOPP; a personal perspective}

\author{
$\mathrm{J} \mathrm{Silke}^{\star, 1,2}$ and JE Vince $\mathrm{e}^{1,2}$ \\ Cell Death and Differentiation (2012) 19, 1-4; doi:10.1038/cdd.2011.166
}

Jürg Tschopp not only made enormous contributions to the fields of cell death and inflammation research, he also inspired discoveries by others. This article is however not an obituary, nor is it in the strictest sense a review of the literature. What we have tried to do is describe a continuing scientific story that acknowledges Jürg's direct and indirect influence with particular reference to our own fields of research, TNF, inhibitor of apoptosis proteins (IAPS) and inflammation.

My first real experiences of Jürg, which later led to James' postdoc with him, was a short sabbatical in the European summer of 2005 in the Department of Biochemistry, Lausanne, Switzerland. With my puritanical upbringing l'd always viewed sabbaticals as long holidays, but the experience in Jürg's lab was so invigorating that I have completely changed my stance and now see them as a catalyst of scientific development.

l'd chosen Jürg's lab because he was an acknowledged expert in the TNF signalling field. He first identified perforin ${ }^{1}$ and, at the same time as another group, characterised its role in cytolytic T-cell mediated lysis. ${ }^{2,3}$ This earlier period of his work is well reviewed in this tribute edition by Chris Bleackley ${ }^{4}$ and Joe Trapani. ${ }^{5}$ But it was his demonstration that Fas (CD95) also contributes to this process ${ }^{6}$ that heralded the beginning of his groundbreaking contributions to the TNF field, reviewed in this issue by Thomas Kaufmann and Andreas Strasser, ${ }^{7}$ and Peter Krammer. ${ }^{8}$ He subsequently identified TNF superfamily (TNFSF) ligands and receptors involved in lymphocyte homeostasis, haematological cancers and auto-immune disease ${ }^{9,10}$ Over the years his laboratory also examined how death and pattern recognition receptors (PRR) signal apoptosis and activate NF- $\kappa \mathrm{B},{ }^{11-14}$ and in two seminal papers identified and characterised how viral FLICE-inhibitory protein (VFLIP) and mammalian cFLIP prevent death receptor killing by inhibiting caspase-8. ${ }^{15,16}$

At the time, however, I was impressed by his dissection of TNF receptor 1 (TNFR1) signalling. In 2003, his lab showed that TNF ligation of TNFR1 results in the rapid formation of a cell surface signalling complex (complex 1) containing TNFR1/TRADD/TRAF2/RIPK1 and cellular inhibitor of apoptosis proteins (clAPs) that activates $\mathrm{NF}-\kappa \mathrm{B}$ to induce the transcription of cytokines and pro-survival genes. ${ }^{17} \mathrm{His}$ insight was to realise that complex 1 did not contain FADD or caspase-8, and that a second death inducing complex (complex 2) containing active caspase-8 formed in the cytosol following TNFR1 internalisation. Similar findings from Stefan Schütze's group demonstrated that TNFR1 complexes must be endocytosed for TNFR1-induced killing to occur. ${ }^{18}$

Jürg's lab therefore was an ideal place to begin exploring what IAPs were doing at TNFSF receptors. Although cIAP1 and clAP2 had been identified binding indirectly to TNFR2 through TRAF2, ${ }^{19}$ and TRAF2 was known, or predicted, to bind to several TNFSF receptors, at this stage no one had clearly identified what clAPs actually did within these signalling complexes. Upon arriving in his lab I was lucky to be on a bench next to Fabio Martinon and was able to interrogate him about a new multimeric protein complex he and Jürg had discovered. They had named it the inflammasome, as it was required for caspase- 1 cleavage of the pro-inflammatory cytokines IL-1 $\beta$ and IL-18 into their mature bioactive fragments. ${ }^{20}$ Jürg's pivotal contribution to this field is nicely reviewed by Maya Saleh. ${ }^{21}$ I was also given unlimited access to the phenomenal collection of reagents that Pascal Schneider had assembled. Along with other helpful lab mates like Margot Thome, Etienne Meylan, Antoine Tinel and Sophie Janssens who have contributed a review on the Piddosome to this edition, ${ }^{22}$ it was obvious that another of Jürg's talents was to assemble great scientists around him. I was surprised to find that Jürg regularly wandered into the lab, not to check whether people were still at work, but to explore some 'crazy' idea he'd just had. His previous crazy ideas included the inflammasome, so it was worth listening to them. Even if (by his own admittance) most of the ideas were unlikely to hold up, the obvious enjoyment that Jürg displayed for the process of scientific discovery was infectious. At the time he was also running two successful companies and to this day I can't work out he juggled it.

My time was soon over, but my head was different; it was full of an excitement that the post-doc period had never killed but had dimmed. My suitcase was also full of the generous gifts of Pascal and Jürg, not Swiss chocolates, but a construct for every TNFSF receptor and every TNFSF ligand. On my return to Melbourne I got to work exploring how IAPs could regulate TNFSF receptors. Soon after I returned, I was lucky to have James join me for his postdoc and things kicked off.

\footnotetext{
'Department of Medical Biology, The University of Melbourne, The Walter and Eliza Hall Institute of Medical Research, Parkville, Victoria, Australia *Corresponding author: J Silke, Department of Medical Biology, The University of Melbourne, The Walter and Eliza Hall Institute of Medical Research, Parkville, Victoria 3052, Australia. Tel: + 6139345 2945; Fax: + 6139347 0852; E-mail: silke@ wehi.edu.au

${ }^{2}$ These authors contributed equally to this work.
} 
We wanted to work with endogenous TNFSF receptors, so we screened every cell line we had with the ligands that Pascal and Jürg had, so generously, given me. Straightaway we found something interesting; that TWEAK ligand bound to every adherent cell line we could test. We showed that it was binding Fn14 and hypothesised that the probable reason for the ubiquitous expression of Fn14 was that many of the growth factors able to stimulate Fn14 induction are present in serum. ${ }^{23}$ As serum promotes wound responses in vivo and in vitro ${ }^{24,25}$ this led us, and others, to propose that TWEAK/ Fn14 might be important in the wound response, tissue remodelling and cancer. ${ }^{26-29}$

We observed that TWEAK engagement of endogenous Fn14 lead to the limited degradation of clAPs. At around the same time we received a smac-mimetic compound from Mark McKinlay, Srinivas Chunduru and Stephen Condon at TetraLogic Pharmaceuticals. Like treatment with TWEAK, smac-mimetic treatment of cells promoted clAP1 degradation (more efficiently than TWEAK) and this led us to hypothesise that smac-mimetics and TWEAK share downstream effects. This hypothesis gave us a considerable advantage in determining how smac-mimetics might work because there was already some literature on TWEAK signalling. One of the unexpected scientific seeds that Jürg's lab planted for us was a paper from Pascal Schneider ${ }^{30}$ who, together with Harald Wajant's group, showed that TWEAK induced TNF to kill Kym1 cells. We therefore proposed that smac-mimetics induced TNF to kill cancer cells. This notion turned out to be correct as we were subsequently able to demonstrate that smac-mimetics induced TNF to kill Kym1 cells, just like TWEAK. ${ }^{31,32}$ We went on to show that smac-mimetics activated NF- $\kappa \mathrm{B}$ and that NF- $\kappa \mathrm{B}$ drove TNF production. Although most cells are normally resistant to TNFR1-induced killing, the loss of clAPs also sensitised tumour cells to death receptor-induced apoptosis. ${ }^{31}$ It was gratifying for us that similar findings were simultaneously made by groups using independently developed smac-mimetics. ${ }^{33-35}$ Even here Jürg had an influence because he introduced us to one of these groups headed by Leigh Zawel in Novartis and encouraged us to share data and co-submit.

One of the open questions that remained was why smacmimetics sensitised cells to TNF killing. Several groups working on this question demonstrated that clAPs ubiquitylate RIPK1, a function that had previously been assigned to the clAP-binding partner TRAF2. clAP ubiquitylation of RIPK1 in response to TNFR1 activation has two significant consequences: (i) ubiquitylated RIPK1 promotes $I_{\kappa} \mathrm{B}$ kinase complex recruitment, and activation and downstream NF- $\kappa \mathrm{B}$ signalling and (ii) ubiquitylated RIPK1 is limited in its association with FADD and caspase- . $^{36-42}$ Hence, smacmimetic treatment sensitises cells to TNF killing by blocking the TNFR1-induced canonical NF- $\kappa$ B pro-survival response and simultaneously promoting the formation of a RIPK1/ FADD/caspase-8-killing complex. clAPs can also regulate the formation of a similar RIPK1 containing death-inducing complex from other receptors such as Fas. ${ }^{43}$ cIAP deletion mimics smac-mimetic treatment and largely prevents TNFR1 from activating canonical NF- $\kappa \mathrm{B}^{44}$ In addition to clAP ubiquitylation of RIPK1, clAPs and their E3 activity are also required for linear ubiquitin chain assembly complex (LUBAC) recruitment to TNFR1. ${ }^{45}$ LUBAC activity increases TNF-induced activation of NF- $\kappa \mathrm{B}$ and also limits TNF-induced killing. ${ }^{45-49}$

In 2009, several groups demonstrated that in the absence of caspase function, death receptors could induce programmed necrosis, termed necroptosis, that was mediated by RIPK1 and RIPK3. ${ }^{50-53}$ Furthermore, the deletion of RIPK3 in mice limited inflammatory responses in cerulein-induced pancreatitis and viral infection. ${ }^{51,52,54}$ Loss of RIPK1 ubiquitylation following smac-mimetic treatment facilitates the formation of RIPK1/FADD/caspase-8/cFLIP complexes that are capable of signalling apoptosis or RIPK1/RIPK3-dependent necroptosis. ${ }^{43,51,55,56}$ Both FADD and caspase-8 negatively regulate RIPK1/RIPK3-induced cell death, probably via proteolytic cleavage of RIPK1 and/or RIPK3, ${ }^{57-59}$ and recent studies show that the death of FADD and/or caspase-8 knockout T-cells and epithelial cells, and embryonic lethality is rescued by the codeletion of RIPK3. ${ }^{60-63}$ The essential downstream substrates of RIPK3 required for necroptosis are still unknown, but mitochondrial dysfunction and the generation of reactive oxygen species (ROS) are believed to be important. ${ }^{53,64,65}$ Again Jürg was ahead of the field having described the requirement for FADD, RIPK1 and RIPK1 kinase activity in a necrotic signalling program mediated by death receptor engagement in $2000 .{ }^{66}$ Jürg certainly found the new findings not only gratifying, because they validated his earlier study, but also exciting, and the excitement of this new area of cell death research is captured in the reviews by Marie Lise Gougeon, ${ }^{67}$ Nele Vanlangenakker and Peter Vandenabeele, ${ }^{68}$ and Pascal Meier and Maurice Darding. ${ }^{69}$

His current work suggested that ROS production may be a modulator of NLRP3/caspase-1 inflammasome formation, ${ }^{70}$ but the source of ROS remained unclear. His lab, and other groups, had recently ruled out NADPH oxidase induced ROS in NLRP3 activation, and his theory was that mitochondrial ROS participated in NLRP3 inflammasome assembly. ${ }^{71}$ Being a lateral thinker Jürg immediately saw the potential link between RIPK3, mitochondrial ROS and NLRP3 function. Although RIPK3 turned out not to regulate known activators of NLRP3 function, it did fit with Jürg's theory that mitochondrial metabolism might hold the key to host innate immune responses and be involved in many disease states, such as type II diabetes, Alzheimer's and Parkinson's, that harbour an underlying inflammatory state. These theories stemmed from studies linking these diseases to defective mitochondrial metabolism and inflammation, and some of these ideas were put forward in one of the the last reviews he wrote. ${ }^{72}$

Of course, back in 2005 Jürg's group, along with several others, had already linked innate immune signalling to the mitochondria through the identification of CARDIF (also known as MAVS/IPS-1/VISA). ${ }^{13,73-75}$ CARDIF is a downstream signal transducer of the cytosolic RNA helicase RIG-I, which detects and responds to viral RNA products to induce $\mathrm{NF}-\kappa \mathrm{B}$ and type I interferon responses. Quite unexpectedly, CARDIF was found tethered by a transmembrane domain to the cytosolic face of the mitochondria and could recruit activated RIG-I through homotypic CARD-CARD domain interactions. Although the reason has not been clearly established, the localisation of CARDIF to the mitochondria is essential for its activation of NF- $\kappa \mathrm{B}$ and type I interferon. ${ }^{73}$ 
However, in line with Jürg's prescient ideas, mitochondrial ROS generation has recently been implicated in the signalling of several PRR, including TLR1, TLR2, TLR4 and RIG-I, and has been linked to enhanced cytokine production in patients suffering from TNFR1-associated periodic fever syndrome. ${ }^{76-78}$

Many of the components involved in innate immune signalling were initially identified as being required for NF- $\kappa \mathrm{B}$ and apoptosis signalling elicited from TNFSF receptors such as TNFR1. CARDIF is a prime example because, together with RIG-I, it has been suggested to form a large signalling platform comprising RIPK1, TRADD, FADD, TANK, TRAF2, TRAF3, TRAF6, TRIM25, clAPs, LUBAC, IRF3 and IRF7. In 2009, when James joined Jürg's lab, it therefore made sense for him to pursue the potential role of IAPs in PRR signalling.

A recent gene duplication event created the clAP1 clAP2 locus and, given the proteins also share $52 \%$ identity, it has been assumed that these IAPs overlap in function. The lack of a strong phenotype in cIAP1, clAP2 and XIAP single-knockout mice re-enforced these ideas. Generating clAP1 and clAP2 double-knockout mice from the single-knockout mice is practically impossible because clAP1 and clAP2 are only separated by $17 \mathrm{~kb}$. Smac-mimetics have overcome this technical problem, and provide specific and potent tools to antagonise clAP1, clAP2 and XIAP function simultaneously. However, several groups have access to these new tools and no sooner would James generate some interesting preliminary data on IAP regulation of PRR than another group would publish similar findings! These studies indicated that clAPs regulate cytokine production mediated by TLR2 and TLR4 through the degradative ubiquitylation of TRAF3, and thereby stimulate MAP kinase activation and cytokine production. ${ }^{79}$ In contrast, it has been proposed that clAP-mediated nondegradative ubiquitylation of TRAF3 and TRAF6 is required for CARDIF-mediated NF- $\kappa \mathrm{B}$ and Type I interferon responses. $^{80}$ Similar to their capacity to ubiquitylate RIPK1 and promote TNFR1-induced NF- $\kappa \mathrm{B}$, clAPs, and potentially XIAP, ubiquitylate RIP2 to promote NOD1- and NOD2dependent inflammatory responses following NOD detection of bacterial peptidoglycans. ${ }^{81-83}$

clAPs constitutively target $\mathrm{NF}-\kappa \mathrm{B}$ inducing kinase for proteasomal degradation and therefore smac-mimetic treatment of cells induces a strong non-canonical NF- $\kappa \mathrm{B}$ response. ${ }^{31,35}$ Jürg's lab had shown that TNFSF receptors that induce a strong non-canonical NF- $\kappa B$ response, such as CD40, could block inflammasome assembly and IL-1 $\beta$ secretion. ${ }^{84}$ James therefore set out to test the hypothesis that inhibition of IAPs and the resulting non-canonical NF- $\kappa \mathrm{B}$ could block inflammasome function. However, smac-mimetic treatment actually caused the activation and cellular secretion of both caspase-1 and IL-1, and enhanced the inflammasome activity of cells cotreated with smac-mimetic and known NLRP3 inflammasome activators. A few knockout mice down the line, including analysis of XIAP, CIAP1 and cIAP2 tripleknockout macrophages and a year or so later, James has now shown that the loss of all IAP function specifically activates the NLRP3 inflammasome (submitted).

Surprisingly, however, NLRP3 signalling does not account for all of the bioactive IL- $1 \beta$ secreted into the cell supernatant following smac-mimetic treatment, because NLRP3 and caspase-1-knockout cells still secrete significant amounts of mature IL-1 $\beta$ despite a complete lack of caspase- 1 activity. This was of significant interest to Jürg because in 1995 he had identified alternate proteases, such as Granzyme A, capable of cleaving precursor $\mathrm{IL}-1 \beta,{ }^{85}$ and caspase-1-independent $\mathrm{IL}-1 \beta$ activation has been shown to occur in vivo following Mycobacterium tuberculosis infection and during joint inflammation or tissue damage. ${ }^{86}$ This is now an area of intense investigation in our lab.

Unfortunately, Jürg passed away before the conclusion of this story but there is no doubt that he left an indelible impression on our work and all who knew him. This article is not an obituary, nor is it a review. It is a personal perspective on our research with reference to, and recognition of, the enormous influence that Jürg and his lab had on it. His influence was not always recorded in shared authorship of our papers, even though it was offered to him, because Jürg considered that he 'hadn't done much'. Whatever his own assessment, Jürg's achievements are humbling. Moreover, his respect for scientific values, his generous and open spirit despite the competitive environment, his encouragement of young scientists and his scientific imagination are a bright legacy for future generations of scientists to aspire to.

Our tribute is part of a wider tribute from authors who work in areas that Jürg contributed to. Some of the reviews have already been highlighted at an appropriate place in this editorial but it is a testament to the breadth of Jürg's influence that there wasn't space to discuss his role in other areas that are also reviewed here, such as the bcl-2 family reviewed by Meike Vogler, ${ }^{87}$ caspase- 2 reviewed by Doug Green and Lisa Bouchier-Hayes, ${ }^{88}$ and autophagy reviewed by Sharad Kumar et al. ${ }^{89}$

\section{Conflict of Interest}

The authors declare no conflict of interest.

Acknowledgements. This work is supported by the National Health and Medical Research Council of Australia and operational infrastructure grants through the Australian Government IRISS and the Victorian State Government OIS.

\footnotetext{
1. Masson D, Tschopp J. J Biol Chem 1985; 260: 9069-9072.

2. Kagi $D$ et al. Nature 1994; 369: 31-37.

3. Lowin B et al. Proc Natl Acad Sci USA 1994; 91: 11571-11575.

4. Ewen CL, Kane KP, Bleackley RC. Cell Death Differ 2012; 19: 28-35.

5. Trapani J. Cell Death Differ 2012; 19: 21-27.

6. Lowin B et al. Nature 1994; 370: 650-652.

7. Kaufmann T, Strasser A. Cell Death Differ 2012; 19: 42-50.

8. Lavrik IN, Krammer PH. Cell Death Differ 2012; 19: 36-41.

9. Hahne $\mathrm{M}$ et al. J Exp Med 1998; 188: 1185-1190.

10. Schneider P et al. J Exp Med 1999; 189: 1747-1756.

11. Schneider $P$ et al. Immunity 1997; 7: 831-836.

12. Bodmer JL et al. Nat Cell Biol 2000; 2: 241-243.

13. Meylan E et al. Nature 2005; 437: 1167-1172.

14. Michallet M-C et al. Immunity 2008; 28: 651-661.

15. Thome $\mathrm{M}$ et al. Nature 1997; 386: 517-521.

16. Irmler M et al. Nature 1997; 388: 190-195.

17. Micheau O, Tschopp J. Cell 2003; 114: 181-190.

18. Schneider-Brachert W et al. Immunity 2004; 21 : 415-428.

19. Rothe $\mathrm{M}$ et al. Cell 1995; 83: 1243-1252.

20. Martinon F, Burns K, Tschopp J. Mol Cell 2002; 10: 417-426.

21. Dagenais M, Skeldon A, Saleh M. Cell Death Differ 2012; 19: 5-12.

22. Janssens S, Tinel A. Cell Death Differ 2012; 19: 13-20.

23. Meighan-Mantha RL et al. J Biol Chem 1999; 274: 33166-33176.
} 
24. Gurtner GC et al. Nature 2008; 453: 314-321.

25. Shaw TJ, Martin P. J Cell Sci 2009; 122: 3209-3213.

26. Winkles JA, Tran NL, Berens ME. Cancer Lett 2006; 235: 11-17.

27. Vince JE, Silke J. Cell Death Differ 2006; 13: 1842-1844.

28. Winkles JA. Nat Rev Drug Discov 2008; 7: 411-425.

29. Burkly LC, Dohi T. Adv Exp Med Biol 2011; 691: 305-322.

30. Schneider $P$ et al. Eur J Immunol 1999; 29: 1785-1792.

31. Vince JE et al. Cell 2007; 131: 682-693.

32. Vince JE et al. J Cell Biol 2008; 182: 171-184.

33. Petersen SL et al. Cancer Cell 2007; 12: 445-456.

34. Gaither A et al. Cancer Res 2007; 67: 11493-11498.

35. Varfolomeev E et al. Cell 2007; 131: 669-681.

36. Wang L, Du F, Wang X. Cell 2008; 133: 693-703.

37. Varfolomeev E et al. J Biol Chem 2008; 283: 24295-24299.

38. Bertrand MJ et al. Mol Cell 2008; 30: 689-700.

39. Mahoney DJ et al. Proc Natl Acad Sci USA 2008; 105: 11778-11783.

40. Vince JE et al. J Biol Chem 2009; 284: 35906-35915.

41. Wong WW et al. Cell Death Differ 2010; 17: 482-487.

42. Dynek JN et al. EMBO J 2010; 29: 4198-4209.

43. Geserick $P$ et al. J Cell Biol 2009; 187: 1037-1054.

44. Feltham R et al. J Biol Chem 2010; 285: 17525-17536.

45. Haas TL et al. Mol Cell 2009; 36: 831-844.

46. Tokunaga $\mathrm{F}$ et al. Nat Cell Biol 2009; 11: 123-132.

47. Gerlach B et al. Nature 2011; 471: 591-596.

48. Tokunaga $F$ et al. Nature 2011; 471: 633-636.

49. Ikeda $\mathrm{F}$ et al. Nature 2011; 471: 637-641.

50. Degterev A et al. Nat Chem Biol 2008; 4: 313-321.

51. He S et al. Cell 2009; 137: 1100-1111.

52. Cho YS et al. Cell 2009; 137: 1112-1123.

53. Zhang DW et al. Science 2009; 325: 332-336.

54. Upton JW, Kaiser WJ, Mocarski ES. Cell Host Microbe 2010; 7: 302-313.

55. Tenev T et al. Mol Cell 2011; 43: 432-448.

56. Feoktistova M et al. Mol Cell 2011; 43: 449-463.
57. Lin Y et al. Genes Dev 1999; 13: 2514-2526.

58. Martinon $\mathrm{F}$ et al. FEBS Lett 2000; 468: 134-136.

59. Feng $S$ et al. Cell Signal 2007; 19: 2056-2067.

60. Ch'en IL et al. J Exp Med 2011; 208: 633-641.

61. Oberst $A$ et al. Nature 2011; 471: 363-367.

62. Kaiser WJ et al. Nature 2011; 471: 368-372.

63. Welz PS et al. Nature 2011; 477: 330-334.

64. Kim YS et al. Mol Cell 2007; 26: 675-687.

65. Vanlangenakker $\mathrm{N}$ et al. Cell Death Differ 2010; 18: 656-665.

66. Holler N et al. Nat Immunol 2000; 1: 489-495.

67. Gougeon ML, Melki M-T, Saïdi H. Cell Death Differ 2012; 19: 96-106.

68. Vanlangenakker N, Vanden Berghe T, Vandenabeele P. Cell Death Differ 2012; 19: 75-86.

69. Darding M, Meier P. Cell Death Differ 2012; 19: 58-66.

70. Dostert $C$ et al. Science 2008; 320: 674-677.

71. Zhou R et al. Nature 2011; 469: 221-225.

72. Tschopp J. Eur J Immunol 2011; 41: 1196-1202.

73. Seth RB et al. Cell 2005; 122: 669-682.

74. Xu L-G et al. Mol Cell 2005; 19: 727-740.

75. Kawai T et al. Nat Immunol 2005; 6: 981-988.

76. Tal MC et al. Proc Natl Acad Sci USA 2009; 106: 2770-2775.

77. Bulua AC et al. J Exp Med 2011; 208: 519-533.

78. West AP et al. Nature 2011; 472: 476-480.

79. Tseng PH et al. Nat Immunol 2010; 11: 70-75.

80. Mao AP et al. J Biol Chem 2010; 285: 9470-9476.

81. Bauler LD, Duckett CS, O'Riordan MX. PLoS Pathog 2008; 4: e1000142.

82. Bertrand MJ et al. Immunity 2009; 30: 789-801.

83. Krieg A et al. Proc Natl Acad Sci USA 2009; 106: 14524-14529.

84. Guarda $G$ et al. Nature 2009; 460: 269-273.

85. Irmler M et al. J Exp Med 1995; 181: 1917-1922.

86. Wittmann M, Kingsbury SR, McDermott MF. Joint Bone Spine 2011; 78: 327-330.

87. Vogler M. Cell Death Differ 2012; 19: 67-74.

88. Bouchier-Hayes L, Green DR. Cell Death Differ 2012; 19: 51-57.

89. Denton D, Nicolson S, Kumar S. Cell Death Differ 2012; 19: 87-95. 